\title{
Coro y acción en La Dorotea: una posible cosmología
}

Chorus and Action in La Dorotea. A "Cosmology"

Matias Spector

University of Chicago, Estados Unidos

\section{Resumen:}

El siguiente trabajo postula la existencia de una cosmología en La Dorotea de Lope de Vega. Por "cosmología" se entenderá la existencia de un fundamento conceptual que justifica la unión entre forma y contenido. Para ello se adoptará como marco teórico las doctrinas gnósticas populares en la España del Siglo de Oro. Primero se ilustrará de qué manera el Coro y la Acción son dimensiones narrativas independientes y opuestas; luego se argumentará que la relación entre estas dos dimensiones puede ser comprendida en analogía a la predeterminación y el libre albedrío; finalmente, se propondrá que el diseño de La Dorotea se fundamenta en el concepto de Redención.

Palabras clave: Lope de Vega, La Dorotea, Cosmología, Doctrinas gnósticas, Coro y acción.

\section{ABSTRACT:}

In this paper I suggest that there is a cosmology inside Lope de Vega's La Dorotea. By “cosmology" I mean a conceptual foundation that justifies the union between form and content. Popular gnostic doctrines in the Spanish Golden age period will provide the theoretical framework for this enterprise. Firstly, I will illustrate that Chorus and Action are independent and opposing narrative dimensions; secondly, I will claim that the relation between both dimensions can be understood through an analogy with predetermination and free will; lastly, I will argue that the design of $L a$ Dorotea is founded on the concept of Redemption.

Keywords: Lope de Vega, La Dorotea, Cosmology, Gnostic doctrines, Chorus and action.

\section{INTRODUCCIÓN}

Para que haya una cosmología dentro de una obra literaria debe haber un fundamento que justifique el orden de sus elementos formales y narrativos. La Dorotea, de Lope de Vega, sorprende por su forma extraña y por su contenido digresivo, y por lo tanto parecería carecer de un fundamento que organice ambas partes. Sin embargo, varios especialistas han procurado buscar un principio organizativo de la heterogénea materia. Para citar unos casos, Fernando Copello apunta a la variedad como principio estético de la obra (2001: 39), y ve en la antítesis un criterio estructurador (2001: 44); Ximena González comprende la estructura de La Dorotea como un conjunto de retazos que, "si bien en principio se presenta esquivo y desconcertante, a la larga termina enlazando su coherencia" (2016: 169); Jennifer Barlow propone usar un sistema de reglas y estrategias como el ajedrez para entender las conductas y las motivaciones de los personajes (2013: 247). Este trabajo intenta hallar en la obra una cosmología, entendiendo por "cosmología" un fundamento conceptual que explique la unión entre forma y contenido. Para ello, se utilizará como marco teórico las doctrinas gnósticas populares en la España del Siglo de Oro. En la primera parte, se ilustrará de qué manera el Coro y la Acción constituyen dimensiones independientes y contrapuestas; en la segunda, se argumentará que la interacción entre el Coro y la Acción puede ser interpretada en analogía a la predeterminación y al libre albedrío; en la tercera, se planteará que el fundamento conceptual de la obra es la idea de redención.

\section{CORO Y ACCIÓN: DIMENSIONES INDEPENDIENTES Y CONTRAPUESTAS}

Existe una extensa bibliografía sobre la función del Coro en el drama clásico. Dos de sus más famosos teóricos fueron Horacio y Schlegel. En palabras de Schlegel, Horacio: "ascribes to it a general expression of moral sympathy, exhortation, instruction, and warning” (1965: 70). Por su parte, Schlegel apunta que:

Whatever it might be and do in each particular piece, it represented in general, first the common mind of the nation, and then the general sympathy of all mankind. In a word, the Chorus is the ideal spectator. (1965: 70) 
Para ambos autores el Coro solo existe en función de la Acción, como comentador o como espectador. Es decir que sin Acción no hay Coro.

Laura Alcoba evoca la diferencia entre el "Coro doroteico" y el "Coro clásico":

S'attachant à la substantifique moelle de la machine dramatique que La Dorotea a enclenchée, à ce que l'on pourrait considérer comme sa formule première (amor / interés / celos /venganza), ils diffèrent profondément des choerus de la tragédie antique qui étaient davantage intégrés dans l'action, à laquelle ils référaient de manière explicite. (2001: 8)

Para la autora, el "Coro doroteico", a diferencia del "Coro clásico", no se halla integrado en la acción porque no refiere a esta de manera explícita. Sin embargo, el "Coro doroteico" sí refiere de manera implícita a la "substantifique moelle" de la obra. Según este punto de vista el "Coro doroteico", al igual que el "Coro clásico", parecería no existir de manera independiente, sino solo en función de la acción, para referir a ella de manera implícita. De modo que difícilmente haya Acción sin Coro.

En este trabajo se argumentará que la Acción y el Coro son dimensiones independientes y paralelas, es decir que una puede existir sin la otra. Cada dimensión desarrolla su propia narrativa. El "Coro doroteico" consta de cinco coros que cierran cinco respectivos actos. Cada coro está encabezado por un tópico: Amor, Interés, Celos, Venganza, Ejemplo. Entre estos títulos así como entre el contenido de cada coro es posible tejer una continuidad argumental. Una potencial interpretación podría ser: el Amor es amenazado por el Interés, de lo que resultan Celos, que devienen en Venganza, cuyo desenlace final puede ser un Ejemplo. Este recorrido narrativo queda ilustrado en el último coro: "Este fin a tus desvelos, / loca juventud, alcanza, / porque amor engendra celos; / celos, envidia y venganza" (2011: 401).

Pero Acción y Coro no son solamente independientes, sino también contrarios. Mientras que la Acción será indeterminada, el Coro será determinado. ${ }^{1}$ En la Acción hay numerosos tipos de indeterminación; para resumirlas, se agruparán en dos: temporales y nominales.

La indeterminación temporal refiere a la mezcla arbitraria del pasado, el presente y el futuro. Alban Forcione ofrece consistentes ejemplos sobre la fragmentaria narratividad de La Dorotea, apuntando que:

Lope moves freely between the past and the present, offering us often only fragments of information and refusing to clarify them or to place them logically or temporally in relation to one another or to the context in which they appear. (1969: 461)

La indeterminación nominal refiere a la ambigüedad de los personajes, tema hartamente comentado por la tradición crítica, que incluye tópicos como las múltiples y confusas referencias autobiográficas o como el cambio de roles en un mismo personaje (de criados a disertantes intelectuales).

En contraste, el Coro es determinado: la disposición ordenada de los elementos, el desarrollo uniforme de los tópicos, el común matiz moral en cada exposición. La voz poética será una autoridad sabia, omnisciente y categórica.

En conclusión, en este apartado se ha demostrado la existencia de dos dimensiones contrapuestas. El Coro, determinado, cuenta con rasgos como la omnipotencia; la Acción, indeterminada, contará con rasgos como la contingencia.

\section{RElación ENTRE EL Coro y LA ACCióN: LA PREDETERMINACión Y EL LIBRE ALBEDRío}

En el acto cuarto de La Dorotea se introducen algunas ideas generales sobre la predeterminación y el libre albedrío. Mientras que los astros pueden predeterminar la vida de los hombres, estos a su vez pueden resistir su influencia a través del libre albedrío: "JUL. ¡Qué cierto es culpar los hombres a la influencia, como si las estrellas hicieran fuerza, siendo la resistencia efeto de la virtud de nuestro albedrío, como lo hicieron el divino Platón y Scipión el Africano!" (2011: 280).

Si se decidiera analizar la relación entre el Coro y la Acción en analogía a la relación entre los astros y las vidas de los hombres, habría que dilucidar cuál esfera establece la predeterminación y cuál ejerce el libre 
albedrío. Puesto que es más viable asumir que lo que tiene cualidad de omnisciente predetermine aquello que tiene cualidad de contingente, el Coro, que es determinado como los astros, debería predeterminar a la Acción, que es indeterminada como la vida humana.

Ahora bien, ¿̇cómo se transforma la idea de predeterminación en un procedimiento formal literario? Por empezar, si cada acto acaba con un coro particular, cada coro debería predeterminar el acto que le antecede. En un contexto literario, el concepto de "predeterminación" se transforma en "pre-estructuración". En efecto, cada coro pre-estructura el acto que le antecede.

Si la estructura sirve como el esqueleto de una obra literaria, la pre-estructura establece instancias obligatorias, postas ficcionales por las que la Acción deberá atravesar. Es necesario apuntar que la Acción, sin importar cuán digresivo sea, deberá someterse a este recorrido.

Amor pre-estructura el acto primero: en la primera mitad se hallan los preámbulos y las condiciones para la pelea entre Fernando y Dorotea (la influencia de Gerarda y de Teodora sobre Dorotea; la influencia del sueño premonitorio sobre Fernando); en la mitad del acto, la escena quinta, se establece la pelea entre los amantes; la segunda mitad tratará de las consecuencias de la pelea (el inicio del viaje de Fernando; el intento de suicidio de Dorotea). A través de la pre-estructura de la Acción se puede bosquejar una representación violenta y peligrosa del amor, coincidente con la expresada en el Coro: "Tirano violento de tiernas edades, / el bien persüades y al mal precipitas, / el fin solicitas del mismo a quien quieres: / tan bárbaro eres.” (2011: 78).

El acto segundo está pre-estructurado por el Interés. Las escenas no se desarrollan lógicamente. Solo hay acumulación: visitas, regalos, objetos. El Interés se representa en términos de abundancia y exhibición.

El acto tercero está pre-estructurado por los Celos. Las escenas parecen recorrer un juego de ajedrez. Los personajes se moverán a ciegas, lentamente, con crecientes sospechas de por medio, hasta la escena nona, cuando los celos estallan en una pelea entre Fernando y Bela.

El acto cuarto está pre-estructurado por la Venganza. Su pre-estructura parece representar la manera en que nace la venganza en el corazón de un hombre. Hay dos acontecimientos análogos, uno en la primera escena y el otro en la última. En la primera escena, Julio concientiza a Fernando del daño que le hizo a Dorotea; Fernando recapacita y restablece la relación con ella. En la última escena, Julio concientiza a Fernando del dolor de Marfisa y de la traición de Dorotea; Fernando recapacita y quiere vengarse de ésta. La Venganza se define en las caras opuestas del amor y la traición.

El último acto está pre-estructurado por el Ejemplo. Aquí culminarán distintas líneas argumentales: las vidas de Gerarda y de Bela (mediante imprevistas muertes); la venganza de Fernando (por accidente: una confusión de cartas); la desdicha de Dorotea (que terminará sin ninguno de sus dos amantes); y la relación entre Fernando y Marfisa (por medio de presagios).

Ahora bien, la hipótesis de la pre-estructuración ayuda a explicar una de las cualidades más llamativas de La Dorotea, que es la peculiar unidad argumental entre los actos de la obra. En efecto, el hecho de que cada acto se halle pre-estructurado por el Coro que le sigue implica que no hay una unidad general de acción. Los acontecimientos deberán interpretarse dentro del acto en que se encuentran enmarcados y no en lógica relación con los acontecimientos de otros actos. De esta manera, algunas situaciones que podrían parecer arbitrarias, como las muertes imprevistas de Gerarda y de Bela, o como las fluctuaciones emocionales de Fernando, tienen perfecto sentido en relación con los Coros que cierran sus respectivos actos.

Así, Coro predetermina a la Acción. Pero para que la analogía con los astros y la vida de los hombres sea completa habrá que demostrar que la Acción ejerce su libre albedrio frente al Coro.

¿Cómo se expresa el libre albedrío en un contexto literario? Si la predeterminación es pre-estructura, el libre albedrío es todo lo que rompe, lo que escapa: todas las digresiones banales e intelectuales; las indeterminaciones nominales y las temporales: que un criado se vuelva intelectual, o que se borren las fronteras entre el pasado, el presente y el futuro. 
En conclusión, mientras que el Coro dispone necesarias instancias ficcionales, la Acción resiste mediante la arbitrariedad y la digresión. Así, es perfectamente natural afirmar que el acto primero trata indeterminadamente del amor, que el segundo trata indeterminadamente del interés, etc.

\section{Fundamento conceptual de La Dorotea: la Redención}

Analizar La Dorotea en analogía con la astrología podría ser arbitrario a menos que se demostrara la relevancia de la materia para su autor. José Manuel Blecua confirma que Lope de Vega leyó repetidas veces de Ficino los comentarios al Simposium platónico y la traducción al latín de las enseñanzas de Hermes Trismegisto en el Poimandres - parte del Corpus Hermeticum-, enseñanzasque incluían un conjunto de doctrinas gnósticas (Suárez Miramón, 2006: 580). Estas doctrinas conciben al Universo como una esfera que "expresa la armonía universal" de "dualidades complementarias": Luz y Oscuridad; Hombre y Dios; Espíritu y Materia; correspondencias resumidas en la frase: "Como es arriba, es abajo" (2006: 582).

Quizás la dicotomía Coro/Acción pueda comprenderse como otra dualidad gnóstica. Por un lado, como se demostró en el apartado uno, Acción y Coro son dimensiones independientes y opuestas, pero por el otro, como se demostró en el apartado dos, hay una correspondencia entre ellos puesto que uno predetermina al otro. En otras palabras, la Acción y el Coro pueden ser entendidos como una dualidad complementaria que constituye el universo de la obra, de lo que se podría afirmar: "Como es en el Coro, es en la Acción".

Asumiendo el gnosticismo como el fundamento formal de La Dorotea, cabe preguntarse acerca del fundamento conceptual.

Ana Suárez Miramón escribe sobre la influencia del gnosticismo en la obra de Calderón: "Espejos y estrellas representan la identidad de tierra y cielo y aquéllas actúan a modo de huella divina capaz de conducir al hombre a una auténtica metafísica de la luz" (2006: 582). En otras palabras, porque lo que está arriba es igual a lo que está abajo, el hombre que camina en la oscuridad puede ser guiado por las estrellas y así llegar a una metafísica de la luz. ¿Pero qué significa exactamente esta "metafísica de la luz"? En De Christiana religione, Ficino dice: "Dios declaró e hizo que no hubiese en el mundo nada deforme, nada despreciable, ya que unió al rey del cielo las cosas terrenas y así, de algún modo, las adecuó a las cosas celestes” (Suárez Miramón, 2006: 583). Si lo que está abajo puede adecuarse a lo que está arriba, entonces lo que hay en la tierra puede ser igual de puro a lo que hay en el cielo. Por lo tanto, la persona que en la tierra alcanza una metafísica de la luz se hace divinamente pura. Es decir que se redime. Detrás de la correspondencia entre el cielo y la tierra yace el concepto de Redención.

¿Podría la correspondencia formal de Coro/Acción de La Dorotea expresar el concepto de Redención? De ser cierto, otra pregunta surge: ¿Redención de quién?

Una pista para responder a estas preguntas puede hallarse en el prólogo a La Dorotea. Allí se menciona la existencia de dos obras, una escrita en la juventud y otra corregida de "la lozanía con que se había criado en la tierna mía” (2011:5). La lozanía es una cualidad atribuida a la Juventud, y por lo tanto la segunda versión, que ya no es más lozana, debería identificarse con la Senectud. Quizá pueda leerse de manera literal la existencia de dos La Dorotea; de hecho, se podría pensar que ambos trabajos, uno de Juventud y el otro de Senectud, se encuentran integrados en la misma obra. Ya Juan Manuel Rozas había afirmado la doble autoría en las últimas obras de Lope de Vega a través de un análisis de frases y versos aislados. Francisco J. Ávila continuó esta tradición crítica en La Dorotea: "Hay en la obra, pues, un núcleo externo, el del asunto Osorio, y otro latente, el de las preocupaciones pragmáticas y literarias de senectud" (1995: 16).

En el presente trabajo, la doble autoría no está localizada en frases o versos, sino en dos dimensiones formales: Coro y Acción. A esta dicotomía, y a otras ya mencionadas (Estrellas y Hombre, Arriba y Abajo) podría agregarse una más: Senectud y Juventud. Mientras la Senectud se asocia con la sabiduría, la omnipotencia y la claridad del Coro, la Juventud lo hará con las digresiones, las contingencias y las indeterminaciones de la Acción. 
Si tal es el caso, debería interpretarse que la Senectud corrige a la Juventud de aquella lozanía, entendiendo la idea de "corrección" no como "reemplazo" sino como "reglamentación": la Senectud reglamenta, corrige, predetermina a la Juventud imponiéndole instancias obligatorias, postas ficcionales por las que la Juventud rebelde, más allá de sus fluctuaciones y resistencias, debe atravesar.

Detrás de la correspondencia entre Coro y Acción yace la idea de Redención. Para que un hombre pueda redimirse es necesario que recuerde; La Dorotea es un ejercicio de memoria que reúne, en la forma y en el contenido, una parte errante y otra que guía. Dentro de La Dorotea hay un diálogo entre la Juventud y la Senectud de una misma persona.En esta tensa relación, el arbitrario y caprichoso joven interactúa con el sabio y omnipotente anciano. No hay culpas ni reproches; solo reglas que llevan a una metafísica de la luz.

Y así es posible hallar en la Redención el fundamento conceptual del diseño de la obra, una cosmografía interna que rige la disposición de la forma y el contenido en La Dorotea. Quedará para un estudio posterior la relevancia autobiográfica del concepto de Redención para Lope de Vega.

\section{Bibliografía}

Alcoba, Laura, 2001. "Présence du tragique dans La Dorotea", en La Dorotea de Lope de Vega, Monique Güell (ed.), Paris: Ellipses, 5-12.

Ávila González, Francisco, 1995. "La Dorotea: arte y estrategia de senectud, entre la serenidad y la desesperación", Edad de Oro, XIV, 9-28.

Barlow, Jennifer, 2013. "Checkmate: The Gifting Game and Gender Performance Anxiety in Lope de Vega's La Dorotea”, Hispanic Review81(3), 245-262.

Copello, Fernando, 2001. “La Dorotea como género abierto” en La Dorotea de Lope de Vega,Monique Güell (ed.), Paris: Ellipses, 37-51.

Forcione, Alban, 1969. "Lope's Broken Clock: Baroque Time in the Dorotea”, Hispanic Review, 37(4), 459-490.

González, Ximena, 2016. “La Dorotea de Lope de Vega: consideraciones en torno a un texto esquivo”, en: Hispanismos del mundo: diálogos y debates en (y desde) el Sur [anexo digital], Leonardo Funes (coord.), Buenos Aires: Miño y Dávila, 167-175.

McGrady, Donald (ed.), 2011. Lope de Vega, La Dorotea, Madrid: Real Academia Española.

Schlegel, August Wilhelm, 1965. Curse of Lectures on Dramatic Art and Literature, Traducción de John Black, New York: AMS Press.

Suárez Miramón, Ana, 2006. "El sistema teológico-estético en Ficino y Calderón”, en: Edad de Oro Cantabrigense. Actas del VII Congreso de la AISO, Anthony Close (ed.), Madrid: Sociedad Estatal de Conmemoraciones culturales-Iberoamericana Vervuert, 579-584.

\section{Notas}

1. Se definirá "indeterminación” como la mezcla amorfa de elementos. 